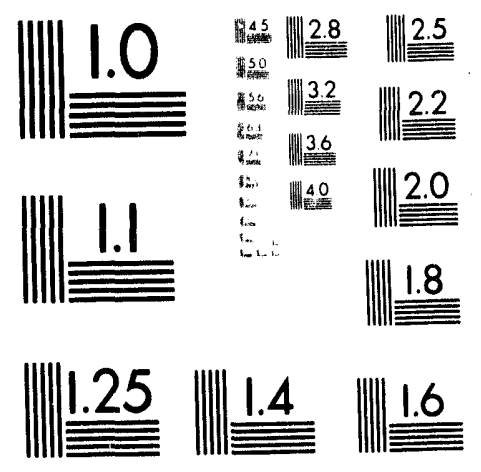



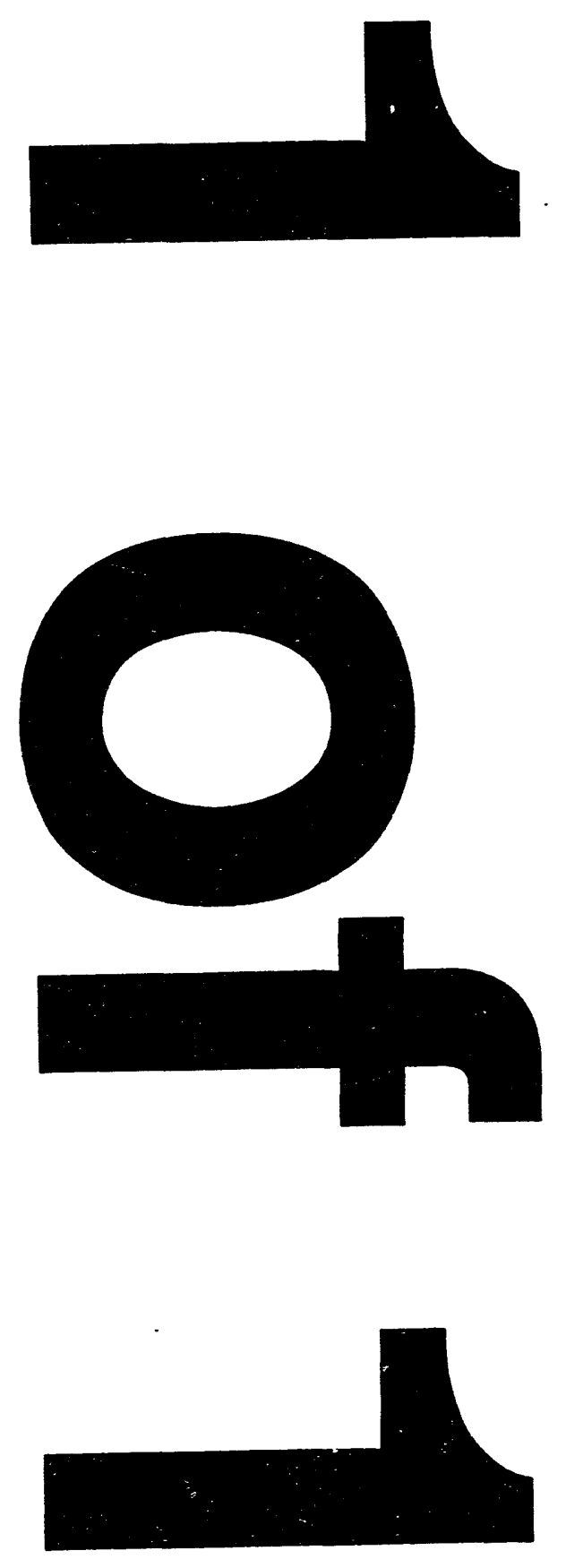


\title{
Material Properties and Fracture Mechanics \\ In Relation to Ceramic Machining
}

\author{
Lee V. Griffith
}

Manuscript date: December 2, 1993 


\section{Contents}

Introduction nact

\section{Figures}

1. Median/radial and lateral crack system inder a square pyramidal indenter .............................. 3

2. Plastic zone of a square pyramidal indenter .......................................................................... 4

3. Tensile stress distribution during loading (upper curve for each value of $\beta$.)

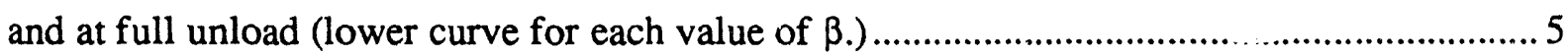

4. Rounded or flat abrasives result in higher threshold loads....................................................... 8

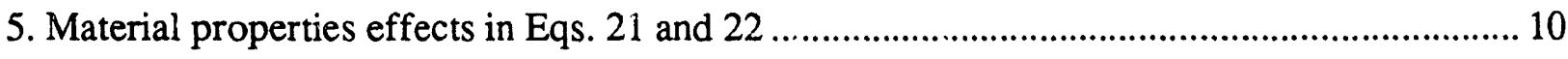

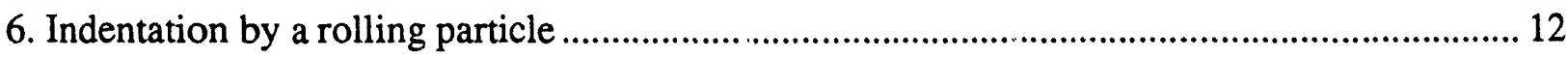

\section{Tables}

1. Material properties and calculated radial and lateral crack initiation loads ............................... 8

2. Material properties dependence in Eqs. 21 and 22 ............................................................ 10 


\title{
Material Properties and Fracture Mechanics in Relation to Ceramic Machining
}

\begin{abstract}
Material removal rate, surface finish, and subsurface damage are largely governed by fracture mechanics and plastic deformation, when ceramics are machined using abrasive methods. A great deal of work was published on the fracture mechanics of ceramics in the late 1970s and early 1980s, although this work has never resulted in a comprehensive model of the fixed abrasive grinding process. However, a recently published model describes many of the most important features of the loose abrasive machining process, for example depth of damage, surface roughness, and material removal rate. Many of the relations in the loose abrasive machining model can be readily discerned from fracture mechanics models, in terms of material properties. By understanding the mechanisms of material removal, from a material properties perspective, we can better estimate how one material will machine in relation to another. Although the fracture mechanics models may have been developed for loose abrasive machining, the principles of crack initiation and propagation are equally valuable for fixer abrasive machining. This report provides a brief review of fracture in brittle materials, the stress distribution induced by abrasives, critical indenter loads, the extension of cracks, and the relation of the fracture process to material removal.
\end{abstract}

\section{Introduction}

Structural ceramics such as silicon nitride, alumina, zirconia, and alumina-zirconia have the potential of becoming a multi-billion-dollar industry. More importantly, these ceramics may provide a competitive advantage to shift market share to companies using these extremely durable materials in critical components. Internal-combustion and turbine-engine components are two of the potentially large markets for ceramic components. In these applications, ceramics can improve efficiency (by reducing heat transfer), provide greater wear life, reduce emissions, and improve reliability. However, ceramic components will not enjoy an easy path to commercial success. Ceramic components must compete with continually improving steel alloys. If ceramics are to displace steel counterparts, the incremental cost of these components must be relatively low. An estimated 50 to $90 \%$ of the cost of a finished advanced ceramic component is due to the cost of machining. Thus the cost-effectiveness of the ceramic machining process has enormo'ss leverage on the growth of the structural ceramic industry and on the competitiveness of associated industry. 
Grinding with both fixed and loose abrasives has been studied with well controlled grinding experiments and through indentation analysis. Each of these methods has specific advantages. Grinding experiments have generally resulted in relatively simple expressions that conveniently relate measurable machining parameters. Some of the most notable work in this area was done more than 70 years ago by F.W. Preston [1]. The equation that Preston developed for three-body wear relates the depth of material removed, $H_{m}$, to the normal force on the workpiece and the distance the workpiece has traveled relative to the lap.

$$
H_{m}=C \frac{L_{n} \cdot g}{A} \Delta S
$$

$C$ is the Preston coefficient, $L_{n}$ is the normal load in $\mathrm{kg}, g$ is gravitational acceleration, $A$ is the area of the work piece in contact with the lap, and $\Delta S$ is the distance the work piece moves relative to the lap. The Preston coefficient is proportional to the inverse of the specific energy of removal, which in the adiabatic case approaches the melting energy for metals [2, p121] or the sensible energy required to reach the decomposition temperature for certain nonmelting ceramics. Unfortunately, the Preston coefficient is not a simple constant, as we will see from the fracture mechanics models. The energy of removal is $E=\bar{F} \cdot \overline{\Delta S}$, a vector product, although the vector notation is normally dropped in favor of the scalar notation $E=F_{t} \cdot \Delta S$, where $F_{t}$ is the tangential force. Malkin [2] describes ine tangential force, $F_{t}$, with three components: one caused by chip formation, $F_{c}$, another caused by plowing, $F_{p}$, and another caused by sliding and viscous drag, $F_{s}$. This formulation would hold for either fixed or loose abrasive grinding. The minimum energy of removal occurs when all of the work goes into chip production. Malkin [2] reports that for steels the minimum specific energy of removal is $u_{\min }=13.8 \mathrm{~J} / \mathrm{mm}^{3}$. We can estimate $u_{\min }$ for silicon nitride as

$$
u_{\min }=c_{p} \rho \Delta T=1150\left(\mathrm{~J} / \mathrm{kg}{ }^{\circ} \mathrm{K}\right) \cdot 3.19 \times 10^{-6}\left(\mathrm{~kg} / \mathrm{mm}^{3}\right) \cdot 1500\left({ }^{\circ} \mathrm{K}\right)=5.5\left(\mathrm{~J} / \mathrm{mm}^{3}\right) \text {. }
$$

\section{Cracks and Indentation}

Two types of cracks are of interest to us: median/radial cracks and lateral cracks. For high-speed grinding, we are generally interested in what is called the far field, which is regarded as the elastic region substantially beyond the plastically deformed region. The near field is also of importance to us, however, because it is essential in describing crack initiation and it dominates the benign "ductile grinding mode." Figure 1 shows the different types of cracks and some of the key dimensions we will use in our discussion. The median and radial cracks are very similar in shape; when fully formed, they are 
frequently referred to as a half-penny. Radial cracks form at the surface, and thus they always have a semi-elliptical or half penny shape. Median cracks are initiated near the lower boundary of the plastic zone. Median cracks begin with a circular or full-penny shape, but as they reach their full extension at the surface they become half-penny like, and indistinguishable from the radial cracks. In practice, median cracks can also propagate at angles off the vertical $(\varphi=0)$ and the crack extension, $c$, is a weak function of this angle.
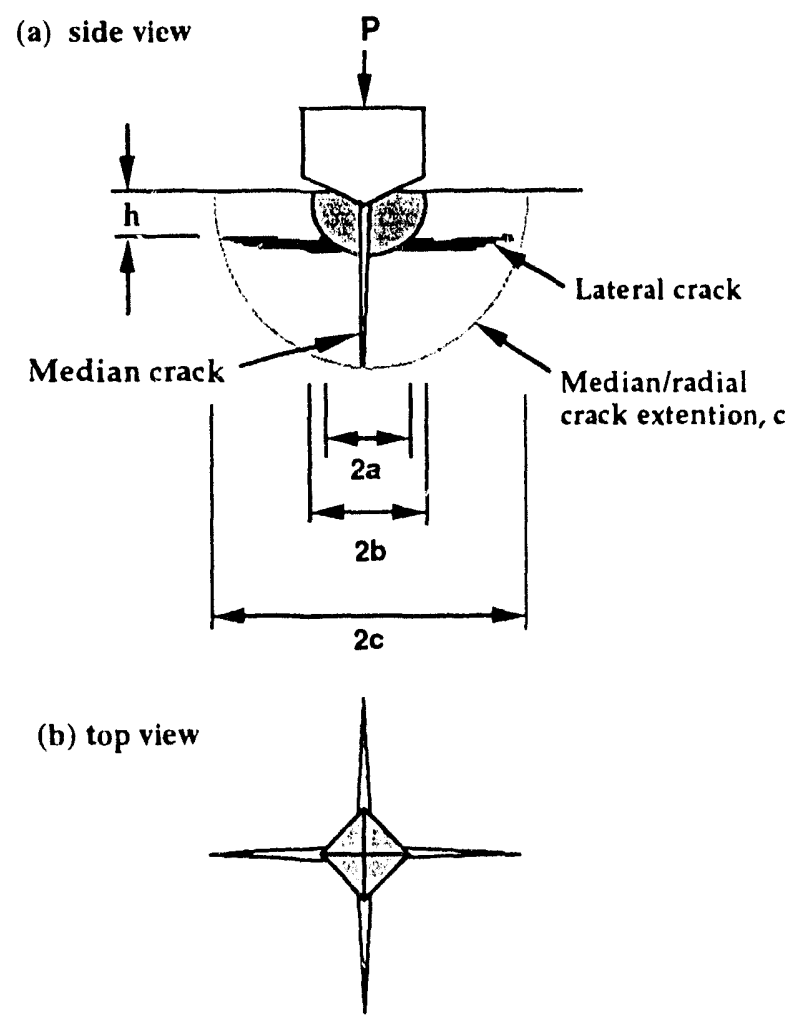

Figure 1. Median/radial and lateral crack system under a square pyramidal indenter.

Indenters of any kind, whether, pyramidal, spherical, or irregular abrasives, produce a plastic zone with a hemispherical plastic/elastic limit [3]. The volume of the hemispherical plastic zone is related to the hemispherical equivalent of the displaced volume of the indenter via the relation [3]

$$
\beta=\left(V_{p} / V_{i}\right)^{1 / 3}=b / a_{e} .
$$

$V_{p}$ is the volume of the hemispherical plastic zone of radius $b . V_{i}$ is the volume displaced by the indenter, which is equivalent to a hemispherical zone, of radius $a_{\ell}$ [4]. Chiang [4] states that $a_{\ell}$ is proportional to the square root of the load applied to the indenter, $P$, divided by the hardness of the workpiece, $H$.

$$
a_{\epsilon}=(0.1 P / H)^{1 / 2} \text {. }
$$


The volume of a pyramidal indenter is $V_{i}=1 / 3$ (depth)(base area). When $2 \psi$ is the included angle between opposite faces of the indenter and $2 a$ is the diagonal of the indentation, then the depth is $h_{a}=\frac{a}{\sqrt{2}} \cot \psi$ and the area is $2 a^{2}$. The relation between the pyramidal indenter diagonal, which is the commonly measured parameter in indentation analysis, and the equivalent radius, $a_{e}$, is now determined by equating the hemispherical equivalent volume and the indenter volume, see Figure 2.

$$
\frac{2 \pi}{3} a_{e}^{3}=\frac{1}{3}\left(\frac{a}{\sqrt{2}} \cot \lambda\right)\left(2 a^{2}\right)
$$

Thus,

$$
\frac{a}{a_{e}}=(\pi \sqrt{2} / \cot \psi)^{1 / 3}
$$

Now, using Eqs 4 and 6, the half diagonal can be expressed in terms of the ratio of the applied load to the hardness, $P / H$.

$$
a=(\pi \sqrt{2} / \cot \psi)^{1 / 3} \sqrt{0.1 P / H}=\sqrt{P / \alpha_{o} H},
$$

where $\alpha_{o}$ is an indenter constant, for example at $\psi=68^{\circ}, \alpha_{o}=2[5,6]$. The ratio of the characteristic lengths of the plastic volume to the displaced volume, $\beta=b / a_{e}$, is a function of the ratio of elastic modulus to hardness. A curve fit to data presented by Chiang [3], for a variety of metals, glass, and ceramics, yields

$$
\beta=0.89(E / H)^{0.38}
$$

Chiang et al. [3] describe the stress field surrounding an indentation in great detail. It is important to note that the limit of the plastic zone is hemispherical irrespective of the indenter shape. Subsequently, the stress field equations based on the characteristic indentation radius $a_{e}$ are applicable for spheres, Vickers indenters, or abrasives near the plastic boundary. The residual stress field takes on the same form as the field when the indenter is under load. The stress field can be expressed as radial and tangential stresses or as the normal stresses along the principal axes. To get a general idea of what the stress fields look like, consider the tangential stress, $\sigma_{t}$, during the loading phase, normalized to the indenter cavity pressure, $p[3]$ :

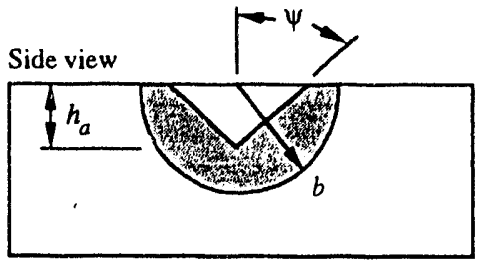

Top view

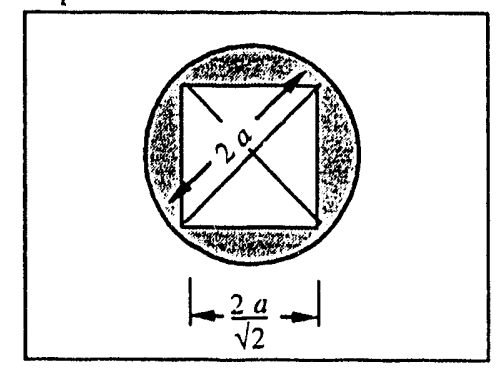

Figure 2. Plastic zone of a square pyramidal indenter. 


$$
\begin{gathered}
\sigma_{t}^{p l} / p=\frac{3\left[\ln \left(r / a_{e}\right)+1 / 2\right]}{1+3 \ln \beta} \quad\left(1<r / a_{e}<\beta\right) \\
\sigma_{t}^{e l} / p=\frac{\beta^{3}}{2\left(r / a_{e}\right)^{3}(1+3 \ln \beta)} \quad\left(r / a_{e}>\beta\right) .
\end{gathered}
$$

The superscripts $p l$ and $e l$ denote the plastic and elastic zones respectively. $r$ is the radial distance from the indenter entry point and the transition from the plastic to elastic zone occurs at $r / a_{e}=\beta$. The equations for the normalized residual stress are very similar in the unloaded state, $P=0$.

$$
\begin{gathered}
\sigma_{t}^{p l} / p=\frac{3\left[\ln \left(r / a_{e}\right)+1 / 2\right]}{1+3 \ln \beta}-1-\frac{1}{2\left(r / a_{e}\right)^{3}} \quad\left(1<r / a_{e}<\beta\right) \\
\sigma_{t}^{e l} / p=\frac{1}{2\left(r / a_{e}\right)^{3}}\left[\frac{\beta^{3}}{(1+3 \ln \beta)}-1\right] \quad\left(r / a_{e}>\beta\right) .
\end{gathered}
$$

These stress distributions are plotted in Figure 3 to illustrate that the peak tensile stresses occur at the boundary between the elastic and plastic zone $\left(r / a_{e}=\beta\right)$ and quickly become compressive toward the center of the plastic region. Lateral cracking is caused by stress in the vertical direction, $\sigma_{z z}$, and these are always maximized in the fully unloaded condition.

Tensile stress

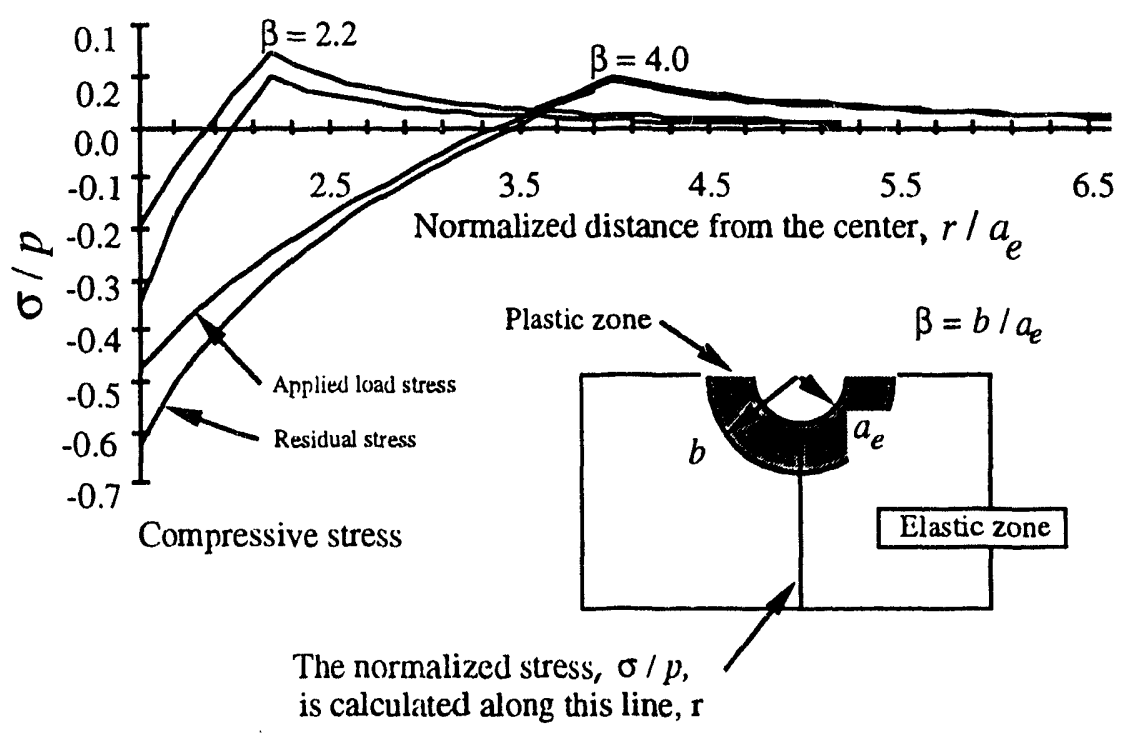

Figure 3. Tensile stress distribution during loading (upper curve for each value of $\beta$.) and at full unload (lower curve for each value of $\beta$.). 
The stress distribution equations above do not include the surface stress relations presented by Chiang [3]. Shear stress introduced by the indenter during the loading phase of the cycle can modify the amplitude by $10-30 \%$. The important point to note from Figure 3 is that the residual stress, that is the stress in the material after the indenter is unloaded, closely approximates the peak stress distribution during the loading/unloading cycle.

\section{Threshold Loads and Crack Extension}

Median cracks may be the first to nucleate because they form during the loading phase, provided that the load is sufficiently high. Radial cracks form during the unloading phase and may initiate at a lower load than the median cracks. The minimum threshold load, $P^{*}$, and the associated crack extension, $\mathrm{c}^{*}$, are a nonlinear functions of the toughness, $K_{I C}$, and the hardness, $H[6]$.

$$
\begin{gathered}
P^{*}=\lambda_{0} K_{I c}\left(K_{I c} / H\right)^{3} \\
c^{*}=\mu_{0}\left(K_{I c} / H\right)^{2} .
\end{gathered}
$$

$\lambda_{o}=1.6 \times 10^{4}$ and $\mu_{0}=120$ provide a good fit to data from a variety of brittle materials [6]. These empirically derived values are substantially higher than predicted for an ideal penny median crack [7].

Measurement techniques and material processing cause some variation in hardness, $H$, and even more variation in toughness, $K_{I c}$, so the ratio of $\left(K_{I c} / H\right)^{3}$ can vary by an order of magnitude. This does not mean that the equation is not useful; it simply implies that we need to know the properties of the particular material to be machined. Loads and crack sizes below $P^{*}$ and $c^{*}$ should result in damage confinement to the near field, which is characterized by the indention parameter, $a$.

Median cracks reach their maximum extension at the peak of the particle loading/unloading cycle $[4,5]$. At the peak load $P=P_{p}$, the radial crack extension is substantially less than the median crack extension. However, in the fully unloaded condition the radial crack extension, $c_{R}$, is about the same as the median crack extension at $P=P_{p}$, [5].

$$
c_{R}=\left\{0.032(\cot \psi)^{2 / 3}\left[\left(\frac{E}{H}\right)^{1 / 2} / K_{l c}\right]\right\}^{2 / 3} P_{P}^{2 / 3} .
$$


Median cracks may close during unloading, but they do not "heal." Material failure may occur as a result of median or radial cracks. The residual strength after indentation is approximately $[5,8]$

$$
\sigma=\left[K_{l c}^{4}\left(\frac{H}{E}\right)^{1 / 2}\right]^{1 / 3} / P_{p}^{1 / 3}
$$

Lateral cracking follows the initiation of median/radial cracks in the loading/unloading cycle. Lateral crack opening is dominated by the residual stress normal to the surface. Lateral cracks can form anywhere around the boundary of the plastic zone and under severe loading several may form at different depths [9]. The largest lateral cracks form at a depth, $h$, roughly equal to the extent of the plastic zone, $b$; thus Marshall et al. [9] write

$$
h \propto b \propto(E / H)^{1 / 2}(\cot \psi)^{1 / 3}\left(P_{P} / H\right)^{1 / 2}
$$

However, if we use Eqs. 4 and 8, we arrive at a slightly different result, which does not depend on $\psi$. This result raises some question of uns:ated conditions on Eq. 4.

$$
h \approx b=0.89(E / H)^{378}(\cot \psi / \sqrt{2} \pi)^{1 / 3}\left(P_{P} / H\right)^{1 / 2} .
$$

The lateral crack length is weakly dependent on the compliance, $A$, and shows a power law dependence on the peak load, $P_{p}$. With severe loads, the lateral cracks extend beyond the median/radial cracks to a limiting crack radius, $c_{L}$ [9]

$$
c_{L}=\left\{\left(\zeta_{L} / A^{1 / 2}\right)(\cot \psi)^{5 / 6}\left[(E / H)^{3 / 4} / K_{I c} H^{1 / 4}\right]\right\}^{5 / 2} P_{p}^{5 / 8} .
$$

$\zeta_{L}=1.6 \times 10^{4}$ was determined experimentally for a variety of materials that span a 4 to 1 range in both $(E / H)$ and $K_{I C}$. The compliance, $A$, is a dimensionless term equal to $3 / 4$ in the near field, that is, where $P_{p}<<P^{*}$. As the load becomes more severe, $P_{p}>>P^{*}$, the compliance is better expressed as a function of the Poisson ratio, $v$ [9].

$$
A=\frac{3}{4 \pi}\left(1-v^{2}\right)
$$

The lateral crack radius can also be expressed as a fraction of the limiting crack extension 


$$
c / c_{L}=\left[1-\left(P_{o} / P_{p}\right)^{1 / 4}\right]^{1 / 2} .
$$

The threshold load, $P_{O}$, is not the same as the threshold for initiation, $P^{*}$, although the material parameter dependence is the same [9], see Table 1.

$$
P_{o}=\left[\zeta_{o} / A^{2}\right](\cot \psi)^{-2 / 3}\left(K_{I c}^{4} / H^{3}\right)(E / H)
$$

\begin{tabular}{|c|c|c|c|c|c|c|}
\hline & $H(\mathrm{GPa})$ & $K_{I c}(\mathrm{M} \mathrm{Pa})$ & $E(\mathrm{GPa})$ & $P^{*}(\mathrm{~N})$ & $c^{*}(\mu \mathrm{m})$ & $P_{O}(\mathrm{~N})$ \\
\hline Coors TTZ & 13 & $8.0-12.0$ & 200 & 72.8 & 71.0 & 298.8 \\
\hline $\mathrm{Al}_{2} \mathrm{O}_{3} \mathrm{ZrO}_{2}$ & 9 & $5.0-6.0$ & 203 & 20.1 & 44.8 & 120.8 \\
\hline $\mathrm{ZrO}_{2}$ & 13 & 7 & 205 & 17.5 & 34.8 & 73.5 \\
\hline $\begin{array}{l}\text { Norton } \mathrm{YZ110 \textrm {HS }} \\
\mathrm{Al}_{2} \mathrm{O}_{3} \mathrm{ZrO}_{2}\end{array}$ & 13.5 & 6.8 & 220 & 13.9 & 30.4 & 60.4 \\
\hline $\begin{array}{l}\text { Norton } \mathrm{AZ} 67 \\
\mathrm{Al}_{2} \mathrm{O}_{3} \mathrm{ZrO}_{2}\end{array}$ & 17 & 7 & 50 & 7.8 & 20.3 & 6.1 \\
\hline Coors ZTA & 14.5 & $5.0-5.5$ & 52.4 & 4.0 & 17.3 & 3.8 \\
\hline $\mathrm{HIP} \mathrm{Si}_{3} \mathrm{~N}_{4}$ & 16 & 5 & $290-307$ & 2.4 & 11.7 & 12.2 \\
\hline $\mathrm{B}_{4} \mathrm{C}$ & $27-31$ & 6 & $360-400$ & 0.9 & 5.1 & 2.97 \\
\hline $\mathrm{Al}_{2} \mathrm{O}_{3}$ & 17 & 4 & 480 & 0.8 & 6.6 & 6.28 \\
\hline $\begin{array}{l}\text { Norton NT154 } \\
\mathrm{Si}_{3} \mathrm{~N}_{4}\end{array}$ & 16 & $3.2-3.5$ & 310 & 0.5 & 5.4 & 2.7 \\
\hline $\mathrm{Al}_{2} \mathrm{O}_{3} / \mathrm{TiC}$ & 19.6 & 3.8 & 390 & 0.44 & 4.5 & 2.35 \\
\hline $\mathrm{SiC}$ & 24 & 4 & 440 & 0.3 & 3.3 & 1.45 \\
\hline BK7 & 5.9 & 0.83 & 80 & 0.04 & 2.4 & 0.13 \\
\hline $\mathrm{SiO}_{2}$ & 6.2 & 0.7 & 72 & 0.02 & 1.5 & 0.05 \\
\hline
\end{tabular}

Table 1. Material properties [17-19 \& vendor data] and calculated radial and lateral crack initiation loads.

Figure 4 shows how the "sharpness" of the abrasive, as characterized by the half angle $\psi$, affects the threshold load for lateral crack formation.

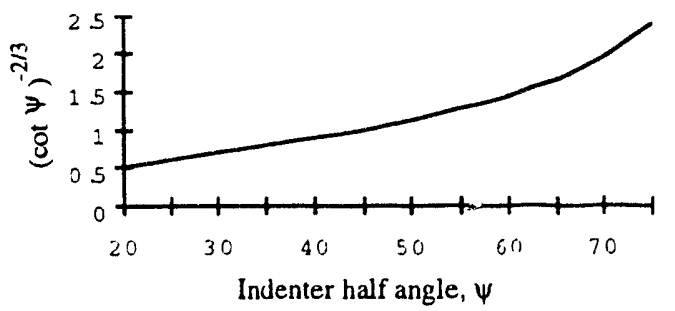

Figure 4 . Rounded or flat abrasives result in higher threshold loads. 


\section{Material Removal Rates, Surface Roughness, and Subsurface Damage}

If wear occurs due to rolling an abrasive particle across the work piece, then the volumetric removal rate should be proportional to $c^{2} h$ and the frequency of indentation, $f$ [9]

$$
\Delta \dot{V} \propto f(\cot \psi)^{4 / 3} \frac{(E / H)^{5 / 4}}{K_{I c} H^{3 / 4}} p^{7 / 4} .
$$

If the abrasive particle is imbedded in the lap, a case more like a bound abrasive, then the volumetric removal rate would be proportional to $c_{L} h v$, where $v$ is the speed of the abrasive relative to the work piece.

$$
\Delta \dot{V} \propto(\cot \psi)^{3 / 4} \frac{(E / H)^{7 / 8}}{K_{l c}^{1 / 2} H^{5 / 8}} v p^{9 / 8} .
$$

This removal rate dependence is very similar to the relationship developed by Malkin and Ritter [10], except that they show the dependence of $(E / H)$ to be the (4/5) power rather than the (7/8) power. Buijs and Korpel-van Houten [11] present a more complete equation for the volumetric removal rate for three body wear.

$$
\Delta \dot{V}=\alpha_{3} n \frac{P_{i}^{3 / 4}}{D_{m c}} \frac{(E / H)^{5 / 4}}{K_{I c} H^{3 / 4}} \vee p_{a} .
$$

In this equation $P_{i}$ is the individual particle load; thus, it has the same meaning as the indenter load, $P$, in the preceding analysis. $\alpha_{3}$ is an abrasive geometry constant with included angle dependence $(\cot \psi)^{7 / 6} . n$ is the number of points on the abrasive particle and $D_{m c}$ is the characteristic dimension of the mean contacting abrasive. Ref. 11 found $D_{m c}$ to be approximately twice the nominal abrasive size, although it seems that this should be pressure dependent. $p_{a}$ and $v$ are the average pressure on the part and the relative velocity between the lap and part, respectively. The material properties kernel of equation 23 ,

$$
\frac{(E / H)^{5 / 4}}{K_{I c} H^{3 / 4}}
$$

is exactly the same as that derived above for rolling particle indentation, in Eq. 21. If we compare the material properties kernel of Eqs. 21 and 22, we see that the imbedded particle should remove material at a factor $10^{4}$ faster than the rolling grit. Table 2 shows how the material properties kernels of equations 21 and 22 compare for various materials. 
Table 2. Material properties dependence in Egs. 21 and 22.

\begin{tabular}{|c|c|c|}
\hline Material & $\frac{(E / H)^{5 / 4}}{K_{l c} H^{3 / 4}}$ & $\frac{(E / H)^{7 / 8}}{K_{l c}^{1 / 2} H^{5 / 8}}$ \\
\hline Coors TTZ & $7.91 \mathrm{E}-14$ & $1.65 \mathrm{E}-09$ \\
\hline $\mathrm{Al}_{2} \mathrm{O}_{3} \mathrm{ZrO}_{2}$ & $3.06 \mathrm{E}-13$ & $3.91 \mathrm{E}-09$ \\
\hline $\mathrm{ZrO}_{2}$ & $1.17 \mathrm{E}-13$ & $2.02 \mathrm{E}-09$ \\
\hline Norton $\mathrm{YZ}^{2} 10 \mathrm{HS} \quad \mathrm{Al}_{2} \mathrm{O}_{3} \mathrm{ZrO}_{2}$ & $1.22 \mathrm{E}-13$ & $2.06 \mathrm{E}-09$ \\
\hline Norton $\mathrm{AZ} 67 \quad \mathrm{Al}_{2} \mathrm{O}_{3} \mathrm{ZrO}_{2}$ & $1.17 \mathrm{E}-14$ & $3.92 \mathrm{E}-10$ \\
\hline Coors ZTA & $2.29 \mathrm{E}-14$ & $5.96 \mathrm{E}-10$ \\
\hline $\mathrm{Si}_{3} \mathrm{~N}_{4}$ & $1.73 \mathrm{E}-13$ & $2.44 \mathrm{E}-09$ \\
\hline$\overline{\mathrm{B}_{4} \mathrm{C}}$ & $5.91 \mathrm{E}-14$ & $1.12 \mathrm{E}-09$ \\
\hline $\mathrm{Al}_{2} \mathrm{O}_{3}$ & $3.46 \mathrm{E}-13$ & $3.75 \mathrm{E}-09$ \\
\hline Norton NT154 & $2.66 \mathrm{E}-13$ & $3.04 \mathrm{E}-09$ \\
\hline $\mathrm{Al}_{2} \mathrm{O}_{3} / \mathrm{TiC}$ & $2.11 \mathrm{E}-13$ & $2.59 \mathrm{E}-09$ \\
\hline $\mathrm{SiC}$ & $1.56 \mathrm{E}-13$ & $2.07 \mathrm{E}-09$ \\
\hline BK7 & $1.47 \mathrm{E}-12$ & $8 . \overline{40 \mathrm{E}-09}$ \\
\hline $\mathrm{SiO}_{2}$ & $1.39 \mathrm{E}-12$ & $7.75 \mathrm{E}-09$ \\
\hline
\end{tabular}

The data in Table 2 are plotted in Figure 5, with $\frac{(E / H)^{5 / 4}}{K_{I c} H^{3 / 4}}$ multiplied by $2 \cdot 10^{4}$ so it will be on the same scale with $\frac{(E / H)^{7 / 8}}{K_{l c}^{1 / 2} H^{5 / 8}}$.

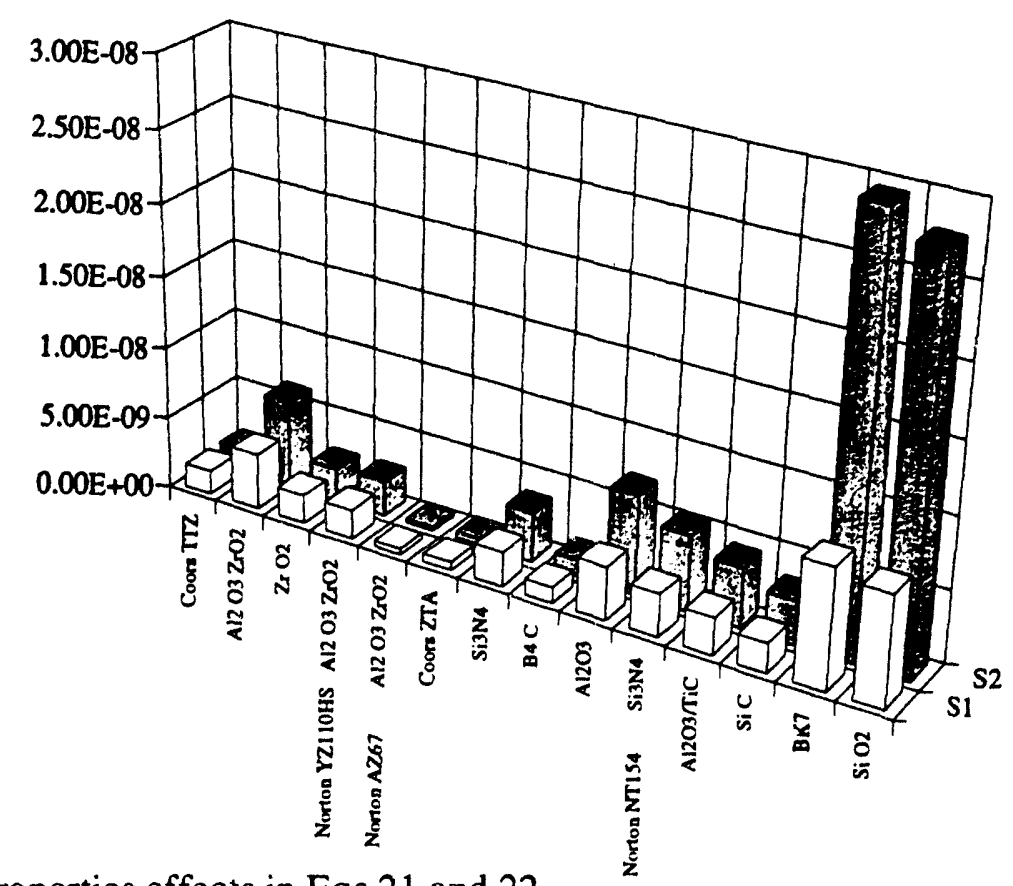

Figure 5. Material properties effects in Eqs 21 and 22. 
Buijs [11] develops the theory that $P_{i}$ is a function of abrasive geometry, slurry fluid properties, and the workpiece and lap material properties. $P_{i}$ is subsequently independent of the average pressure, $p$. Buijs and Korpel-van Houten [11] state that a particle acts on the work piece and the lap with equal force, $P_{i}$. If the particle is idealized as two opposing indenters, as in Figure 6, with included angles $2 \psi_{w}$ and $2 \psi_{l}$, then the load on each particle would be

$$
P_{i}=2 \times\left(\tan \psi_{w}\right)^{2} d_{w}^{2} H_{w}=2 \times\left(\tan \psi_{l}\right)^{2} d_{l}^{2} H_{l}
$$

The subscripts $w$ and $l$ refer to the work piece and lap respectively, and $d$ is the depth of penetration of an indenter. The equation above is obvious from the relationship for hardness measured with a pyramidal indenter with the diagonal length equal to $2 a$, because $a^{2}=P / 2 H$ and the depth, $d=h_{a}=\frac{a}{\sqrt{2}} \cot \psi$.

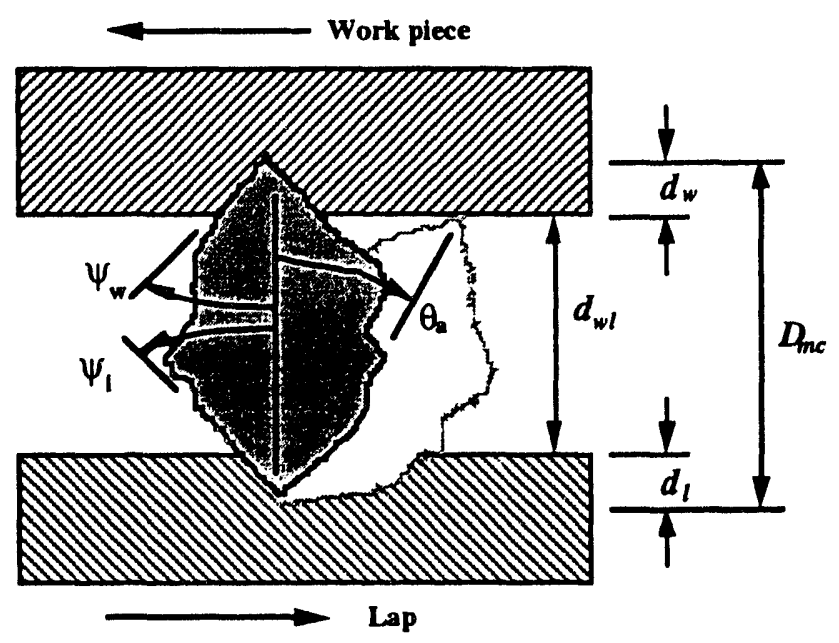

Noting that the separation between the lap and work piece, $d_{w l}$, plus the sum Figure 6 . Indentation by a rolling particle. of the depths of penetrations must equal the characteristic dimension of the mean contacting abrasive, $D_{m c}$, Buijs and Korpelvan Houten [11] write

$$
P_{i}=H_{e f f}\left(1-\frac{d_{w l}}{D_{m c}}\right)^{2} D_{m c}^{2}
$$

where the effective hardness is

$$
H_{e f f}=\frac{2 \tan \psi_{w} H_{w}}{\left[1+\left(2 \tan \psi_{w} H_{w} / 2 \tan \psi_{l} H_{l}\right)^{1 / 2}\right]^{2}}=\frac{2 \tan \psi_{l} H_{l}}{\left[1+\left(2 \tan \psi_{l} H_{l} / 2 \tan \psi_{w} H_{w}\right)^{1 / 2}\right]^{2}}
$$

The term $d_{w l} / D_{m i c}=\cos \theta_{a}$ was described by Phillips et al. in 1977 [12]. Phillips refers to $d_{w l}$ as the "bed thickness" and $\theta_{a}$ as the attack angle, which is a measure of the angle through which the particle must rotate from the peak indentation to the free surface. In 
Phillips' model, $\theta_{a}$ is related to the drag coefficient, $c_{d}$, because most of the sliding force is due to the force required to indent the materials

$$
c_{d}=-\ln \left(\cos \theta_{a} / \theta_{a}\right)
$$

The drag coefficient is measurable for any given slurry fluid, abrasive, lap and work piece combination. Phillips shows that the slurry fluid can have a significant effect on the bed thickness or, more to the point, the depth of penetration and thus the removal rate.

We can also write an expression for the surface roughness that should be proportional to the depth of the lateral cracks,

$$
R \propto h=\alpha_{1}(E / H)^{1 / 2}(\cot \psi)^{1 / 3}(P / H)^{1 / 2} .
$$

Buijs and Korpel-van Houten suggest that $\alpha_{1}=0.71$ for a pyramidal indenter. If $\alpha_{1}$ was well defined, we would have a valuable relation between surface roughness, which is easily measured, and subsurface damage, $R / c \propto h / c$

$$
\frac{h}{c} \approx \frac{f_{2} K_{l c}^{2 / 3}}{H^{1 / 2}}
$$

where $f_{2}$ is essentially a constant, because it has only $\left(1 / 6^{\text {th }}\right)$ and $\left(1 / 9^{\text {th }}\right)$ order dependence on $(E / H), \cot \psi$, and $P_{p}$.

Glasses can clearly be ground in either the fracture or the ductile mode $[10,13,14,15]$. The relatively low threshold load for fracture initiation, $P^{*}$, is easily achieved in either loose or fixed abrasive grinding. Average work piece pressures in three body machining are commonly in the range of $5-20 \mathrm{kPa}$ and if the number of active grits per unit area is in the range of $10^{4}-10^{5} \mathrm{~m}^{-2}$ [11], then the per particle load would be around $0.2 \mathrm{~N}$. This is 5 times the threshold indenter load for BK7,0.04 N. The active grit density cited by Buijs [11] is surprisingly low, and there is no discussion of the derivation of the number to indicate how it would change with grit size.

With a fixed abrasive, where the concentration, $K$, is 4 times the ratio of the volume of grit to the volume of grit plus binder, expressed as a percentage, then the surface density can be approximated as

$$
\frac{N}{A}=\left(\frac{3 K}{200 \pi D^{3}}\right)^{2 / 3}
$$


$N / A$ is the number of grits per unit area, and $D$ is the characteristic diameter of the particle. The number of active grits per unit area should be some fraction of $N / A$.

The contact area in cylindrical grinding is a function of the width of the wheel, radii of the wheel and work piece, and the infeed. However, in very light grinding the contact area might be better expressed in terms of deformation. The width of the contact patch of two contacting cylinders, with parallel axes, is [16]

$$
a_{c}=\frac{4 L_{n} R}{\pi E^{*}},
$$

where $L_{n}$ is the total normal load and $R$ and $E^{*}$ are defined as

$$
\begin{gathered}
R=\frac{R_{s} R_{w}}{R_{s}+R_{w}} \\
E^{*}=\frac{E_{s} E_{w}}{\left(1-v_{s}\right) E_{w}+\left(1-v_{w}\right) E_{s}},
\end{gathered}
$$

$R_{S}$ and $R_{W}$ are the radii of the grinding wheel and work piece, respectively.

If the per-particle loads are below the threshold value, $P<<P^{*}$, then the material removal process is dominated by deformation and the controlling material parameter is hardness [6, 16]. If we assume that an abrasive particle rolls across a surface, then the material removal rate should be proportional to the volume of the hemispherical equivalent radius, $a_{e}$,

$$
\dot{V} \propto \frac{2 \pi}{3 \pi D \Delta t} \frac{n \Delta S}{\pi D} a_{e}^{3} \propto \frac{n v}{D}(P / H)^{3 / 2} .
$$

The term $\frac{n \Delta S}{\pi D}$ represents the number of indentations the grit makes as it rolls a distance $\Delta S$ in time $\Delta t$, with $n$ indenting points. If the particle is embedded, then the removal rate is proportional to the cross sectional area of the indentation and the velocity, $v$,

$$
\dot{V} \propto \frac{\pi}{2} a_{e}^{2} \frac{\Delta S}{\Delta t} \propto v \frac{P}{H} .
$$

Both of these mechanisms should play a role in three-body wear, and the latter should hold in ductile grinding. It must be emphasized that these relations are derived from a speculative premise, that the contact area is deformation controlled, and there are no collaborating data. 


\section{Wear by Adhesion}

McClintock [16] also describes wear by adhesion where particles are transferred from one body to another. Adhesion is the process of pulling a particle off one surface and adhering it to another passing surface. Archard proposed a model of the process in 1953, where he assumed that two sliding surfaces would have $n$ circular contact points or junctions, each with an area $\pi D_{j}^{2} / 4$, where $D_{j}$ is the diameter of the junction. He assumed that each contact would have a probability $K_{p}$ of forming a hemispherical fragment of volume $\pi D_{j}^{3 / 12}$. The real contact area of two surfaces is the total normal load divided by the hardness, $A_{r}=P_{n} / H$, thus the number of contact points is $n_{i}=A_{r} /\left(\pi D_{j}^{2 / 4}\right)$. The number of contacts that would occur in a distance $\Delta S$ is $N_{S}=n_{i} \Delta S / D_{j}$, thus the volume of material transferred by adhesion is [16]

$$
\frac{\Delta V}{\Delta S}=N_{S} K_{p} \frac{\pi D^{3}}{12}=\frac{K_{p} P}{3 H}
$$

Only a small fraction ( $1 / 3$ to $1 / 1000)$ of material transferred by adhesion becomes loose fragments, and the addition of a lubricant can further reduce material removal by a factor of more than $10^{4}[16]$. One other interesting empirical relation of adhesive wear is that when two materials of different hardnesses slide across each other, the softer will wear faster than the harder, according to the inverse square of the hardness ratio [16].

$$
\frac{\text { Wear }_{S}}{\text { Wear }_{H}}=\left(\frac{H_{H}}{H_{S}}\right)^{2} \text {. }
$$

\section{Conclusions}

The fracture mechanics model of material removal provides valuable insights about ceramic machining, but the models remain more qualitative than quantitative. High speed or fracture mode machining of the tougher ceramics will require high per grit load, $P$, as indicated in Table 1. Breaking strength should decline in proportion to the inverse cube root of the load, but the grinding rate should increase by many orders of magnitude as the load rises above the fracture threshold. 


\section{References}

1. F.W. Preston, The structure of abraded glass surfaces, Trans. Opt. Soc., 23, 1921, 141-164.

2. S. Malkin, Grinding Technology: Theory and Applications of Machining with Abrasives, John Wiley \& Sons, New York, 1989.

3. S.S. Chiang, D.B. Marshall, and A.G. Evans, The response of solids to elastic/plastic indentation. I. Stresses and residual stresses, Journal of Applied Physics, 53 January 1982, 298-311.

4. S.S. Chiang, D.B. Marshall, and A.G. Evans, The response of solids to elastic/plastic indentation. II. fracture initiation, Journal of Applied Physics, 53, January 1982, 312-317.

5. B.R. Lawn A.G. Evans, and D.B. Marshall, Elastic/plastic indentation damage in ceramics: the median/radial crack system, Journal of the American Ceramic Society, $63,9-10$, Oct. 1980, 574-581.

6. B.R. Lawn and D.B. Marshall, Hardness, toughness, and brittleness: an indentation analysis, Journal of the American Ceramic Society, 62, Aug. 1979, 347-350.

7. B.R. Lawn and A.G. Evans, A model for crack initiation in elastic/plastic indentation fields, Journal of Material Science, 12, 1977, 2195-2199.

8. D.B. Marshall, B.R. Lawn, P. Chantikul, Residual stress effects in sharp contact cracking; part 2 strength degradation, Journal of Materials Science 14, 1979, 22252235 .

9. D.B. Marshall, B.R. Lawn, and A.G. Evans, Elastic/plastic indentation damage in ceramics: the lateral crack system, Journal of the American Ceramic Society, 65, 11, Nov. 1982, 561-566.

10. S. Malkin and J.E. Ritter, Grinding mechanisms and strength degradation for ceramics, ASME Transactions-Journal of Engineering for Industry, 111, May 1989, $167-173$.

11. M. Buijs and K. Korpel-van Houten, Three-body abrasion of brittle materials as studied by lapping, Wear, 166, 1993, 237-245.

12. K. Phillips, G.M. Crimes, and T.R. Wilshaw, On the mechanism of material removal by free abrasive grinding of glass and fused silica, Wear, 41, 327-350, 1977.

13. N.J. Brown, Optical Fabrication, Lawrence Livermore National Laboratory, Misc. 4476, Rev. 1, Sept. 1990.

14. M. Huerta, and S. Malkin, Grinding of glass: surface structure and fracture strength, Transactions of the ASME Journal of Engineering for Industry, May 1976, 468-473.

15. M. Huerta and S. Malkin, Grinding of glass: the mechanics of the process, Transactions of the ASME Journal of Engineering for Industry, May 1976, 459-467.

16. F.A. McClintock and A.S. Argon, Editors, Mechanical Behavior of Materials, Addison Wesley Publishing Co. 
17. Engineering Property Data on Selected Ceramics, Vol. I Nitrides, Metals and Ceramics Information Center, Battelle Columbus Division, Columbus, Ohio.

18. Engineering Property Data on Selected Ceramics, Vol. II Carbides, Metals and Ceramics Information Center, Battelle Columbus Division, Columbus, Ohio.

19. Engineering Property Data on Selected Ceramics, Vol. III Single Oxides, Metals and Ceramics Information Center, Battelle Columbus Division, Columbus, Ohio. 
